\title{
The Effect of Beach Nourishment on Juvenile Green Turtle Distribution Along the Nearshore of Broward County, Florida
}

\author{
C. Makowski ${ }^{*}, 1$ and L. Fisher ${ }^{2}$ \\ ${ }^{I}$ Marine Science \& Biological Research Department, Coastal Planning \& Engineering, Inc., Boca Raton, Florida, USA \\ ${ }^{2}$ Environmental Protection \& Growth Management Department, Broward County, Florida, USA
}

\begin{abstract}
Juvenile green sea turtles (Chelonia mydas L.) aggregate and develop to maturity in nearshore coastal habitats, putting them in close proximity to beach restoration projects. This study's objective was to determine if the Broward County Shore Protection Project negatively altered the distribution of green turtles along the County's shallow $(\leq 8 \mathrm{~m})$ reef systems. For five consecutive years, 'Shark Fishing' surveys were conducted to record abundance estimates and distribution profiles before and after completion of the beach nourishment project. While pre-construction surveys revealed the natural fluctuation of sea turtle abundance within the nearshore waters, a universal decline in turtle sightings was recorded for both the project area (25\%) and the control site (12\%) after beach construction activities. Even so, the distribution of turtles was not adversely affected or skewed, as $89 \%$ of the turtles sighted during post-construction surveys within the project area were recorded along reef resources adjacent to the beach fill reaches.
\end{abstract}

\section{INTRODUCTION}

Green turtle (Chelonia mydas L.) hatchlings migrate offshore and spend 3-5 years in a sustained pelagic stage, feeding and growing in the open ocean. Unlike other species of sea turtles, greens often return to shallow coastal waters as sexually immature, 'dinner-plate' sized (i.e. $\leq 65 \mathrm{~cm}$ straight carapace length) juvenile turtles [1]. As juvenile green turtles aggregate along coastal reef habitats, they gradually complete a dietary shift from omnivory to herbivory, feeding upon benthic marine flora (i.e. macroalgae and seagrass) in the nearshore [2,3] (Fig. 1). Recent studies have shown that juvenile greens exhibit home ranging behavior and foraging site fidelity, as they may be observed at any one site on a daily basis, and when displaced, return to the same site [4-6]. This feature of their ecological behavior suggests, at any one time and place, systematic observations will provide an accurate estimate of overall population size and distribution within a local region.

Conservation efforts, such as the Florida SNBS (Statewide Nesting Beach Survey) and INBS (Index Nesting Beach Survey) programs, have been focused towards nesting females and hatchling success [7], however, little has been done to assess juvenile green turtle populations along shallow reef habitats. Until recently, there have been no systematic or quantitative studies available to determine turtle abundance along any of the South Florida nearshore reef systems. Makowski (2005) [8] describes the 'Shark Fishing' towed-diver survey technique that can estimate the abundance and distribution of juvenile green turtles in shallow water developmental habitats. 'Shark Fishing' surveys aid in

\footnotetext{
*Address correspondence to this author at the Marine Science \& Biological Research Department, Coastal Planning \& Engineering, Inc., Boca Raton, Florida, USA; Tel: 1-561-391-8102; Fax: 1-561-391-9116;

E-mail: CMakowski@coastalplanning.net
}

identifying juvenile turtles and their preferred range so conservation managers can take appropriate steps to protect endangered populations. In many areas, reefs that supply the necessary vegetation for juvenile greens to reach sexually maturity are located within nearshore (i.e. $\leq 8 \mathrm{~m}$ deep) waters; thus, putting these developmental habitats in close proximity to beach protection projects [6].

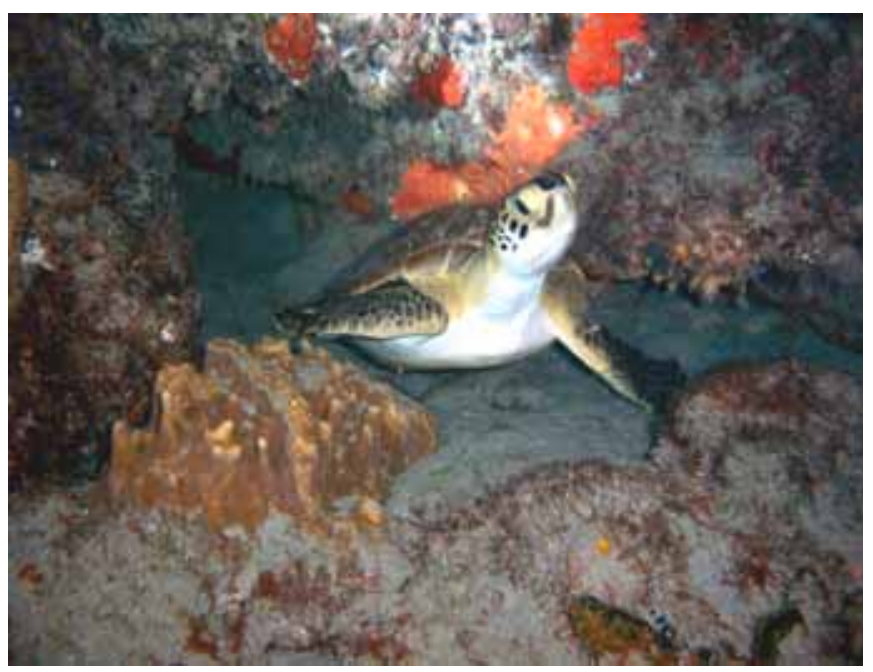

Fig. (1). Juvenile green turtles (Chelonia mydas L.) utilize the reef in the nearshore zone of Broward County, Florida, as either foraging areas or refuge sites.

In 2005/06, the Broward County Shore Protection Project - Segment III was conducted between Port Everglades and the Broward/Miami-Dade County line. The project fill area was approximately $10.97 \mathrm{~km}$ in length and provided beach nourishment for the majority of the County Segment III coastline, including John U. Lloyd State Park, Dania Beach, and the Hollywood/Hallandale shorelines. The estimated sand fill volume for this project was approximately 1.92 mil- 
lion cubic yards (mcy) of approved beach-compatible sand [9].

The objective of this pilot study was to determine if the distribution of juvenile green turtles would be affected by beach construction activities. For the past five years, 'Shark Fishing' surveys have been conducted in Broward County, Florida, to see if the patterns of aggregation within the juvenile populations altered between pre-construction and postconstruction events. Our goal was to reveal if turtles would completely avoid habitats parallel to beach fill areas, thereby leading to a higher cropping of marine vegetation in other areas.

Overall, juvenile sea turtle population records assist conservation managers and environmental regulatory agencies by providing data on turtle presence over specific reef

resources. An annually updated geodatabase of turtle sightings allows conservationists to assess effects that beach nourishment activities may have on resident sea turtle populations, and to determine if these effects cause either temporary fluctuations or long-term variation in the population dynamic. With such knowledge, managers will be better positioned to protect specific reef resources, and the endangered juvenile green turtles that depend upon them during this important stage of their development.

\section{MATERIALS AND METHOLOGY}

\section{Project Area}

The Broward County shoreline is subdivided into three Segments (I, II, and III) for the purposes of the County's shore protection management program (Fig. 2). Segments II and III are delineated by the Florida Department of Environmental Protection (FDEP) survey R-monuments, and were the only areas surveyed for juvenile sea turtle populations in this study. Segment II was $18.3 \mathrm{~km}$ in length, and extends from Hillsboro Inlet (R-25) to Port Everglades Inlet (R-86). Segment III was $13.3 \mathrm{~km}$ in length, and extends from Port Everglades Inlet (R-86) to the Broward County/Miami Dade County Line (R-128).

The Broward County Shore Protection Project - Segment III was constructed from May 14, 2005 through February 8, 2006. The project resulted in the placement of an estimated 1.92 mcy of approved sand along two reaches of beach, the John U. Lloyd Beach State Park (JUL) shoreline and the Hollywood/Hallandale/Dania (HHD) shoreline. The JUL beach fill project area extended from R-86 to R-92 (northern reach of Segment III), and received approximately $0.54 \mathrm{mcy}$ of sand. The HHD beach fill project area extended from R99 to R-128 (central and southern reaches of Segment III), and received approximately 1.39 mcy of sand. Fill placement was eliminated between R-92 and R-99 to minimize potential impacts. Segment II received no beach fill and served as a 'no construction' control [9].

\section{Survey Procedures}

The 'Shark Fishing' technique consisted of a towed diver survey method that documented the abundance and distribution of sea turtle populations with no handling and minimal disturbance to individual turtles [8]. Single vector transects were plotted over, and limited to, the first landward reef tract within Broward County. All surveyed habitat was located in water depths less than $8 \mathrm{~m}$ and ran parallel to both the Segment III beach construction experimental area and the Segment II control site. Each survey was performed in the late Spring/Summer of the appropriate year, when juvenile green turtle recruitment in nearshore waters is estimated to be the highest [10].

Surveys were performed once in a north-bound direction and once in a south-bound direction, and always on different days. Two in-water observers were towed approximately 10 $\mathrm{m}$ behind a slowly moving (1.5-2.0 knots) research vessel (Fig. 3). The in-water observers visually scanned the area directly below and to the left (port observer), and directly below and to the right (starboard observer), to the extent of the visibility underwater (typically, $\sim 10 \mathrm{~m}$ ). Towed divers reported turtle sightings to on-vessel personnel, who then took a locational fix for that specific sighting. Each sighting was recorded on a laptop computer and identified via a Trimble AgGPS Differential Global Positioning System (DGPS) with Pro Beacon interfaced to the Coastal Oceanographic Hydrographic Data Collection and Processing (HYPACK $^{\circledR}$ MAX) program. The HYPACK ${ }^{\circledR}$ MAX software was used to store exact turtle positions along the reef, as well as the time and date of the observation. Other data (e.g. weather conditions, underwater visibility, behavior of the turtle) were added to each sighting from the field notes.

After being located, the turtles usually swam in a perpendicular direction away from the boat, decreasing the chances of being recounted. In addition, onboard observers recorded the positions of surfacing turtles. During all surveys, turtles were never touched or put at risk.

\section{Data Analysis}

Using ArcView version 9.2 geographic information system (GIS) software, all turtle sightings were plotted on laser airborne depth sounder (LADS) contour maps and incorporated into a spatial-controlled geodatabase, which supplied an interactive platform to analyze the turtle's positional data (Fig. 4). Overall turtle abundance was recorded for all five surveying years and applied to a single-factor analysis of variance test (ANOVA), which determined if the Broward County juvenile population had significantly changed as a whole over time. Paired $T$-tests were performed to reveal that the survey data was consistent among pre-construction and post-construction events. Once similarities were established, a non-parametric Mann-Whitney rank sum U test was carried out to show if there were significant differences in turtle sightings between the pre- $v s$ post- treatments for both the Segment II control site and the Segment III experimental area. Analyses were conducted with SPSS software; significance was based on $P<0.01$, as survey sample sizes were not sufficiently large enough to provide a reasonable approximation of the sampling distribution over time.

Percentage comparisons were made to see possible trends that beach construction activities may have had on juvenile turtle populations. The percent difference of pre-construction versus post-construction events was calculated for turtle observations within the Segment II control site and the Segment III experimental area. Also, comparisons of sighting distribution revealed the percent of turtle observations along project fill areas in Segment III versus those that avoided 


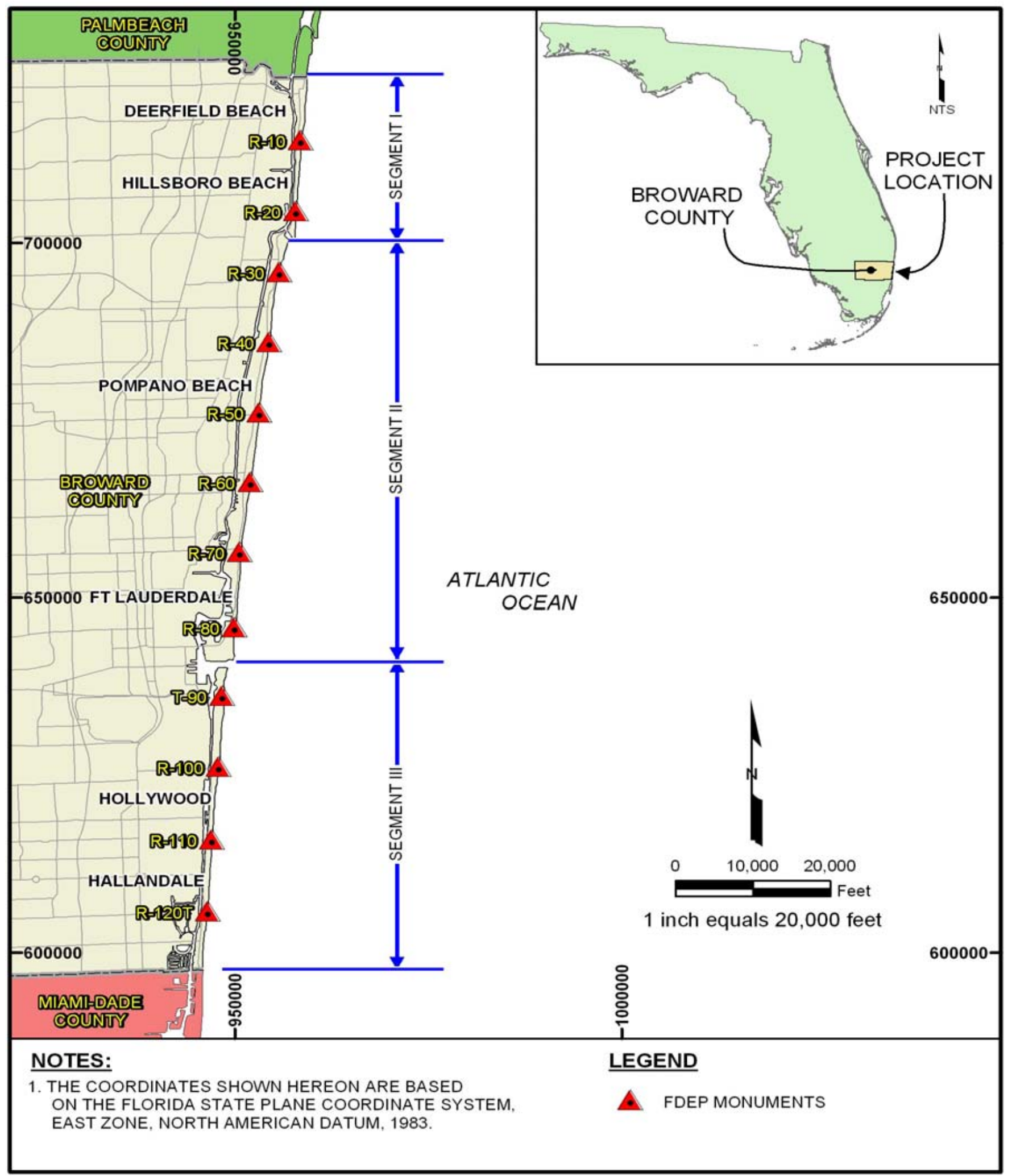

Fig. (2). The Broward County, Florida shoreline, including the Segment II control site and the Segment III experimental area. The following figure is NTS.

such areas. Due to differences in habitat characteristics between Segment II and Segment III (e.g. water clarity, reef structure, resident marine flora, etc.) direct comparison of the two Segments was not deemed scientifically valid. Mean values are followed by their standard deviation, unless otherwise noted. Percentage comparisons do not carry a level of power, and thus should not be considered significant/nonsignificant. 


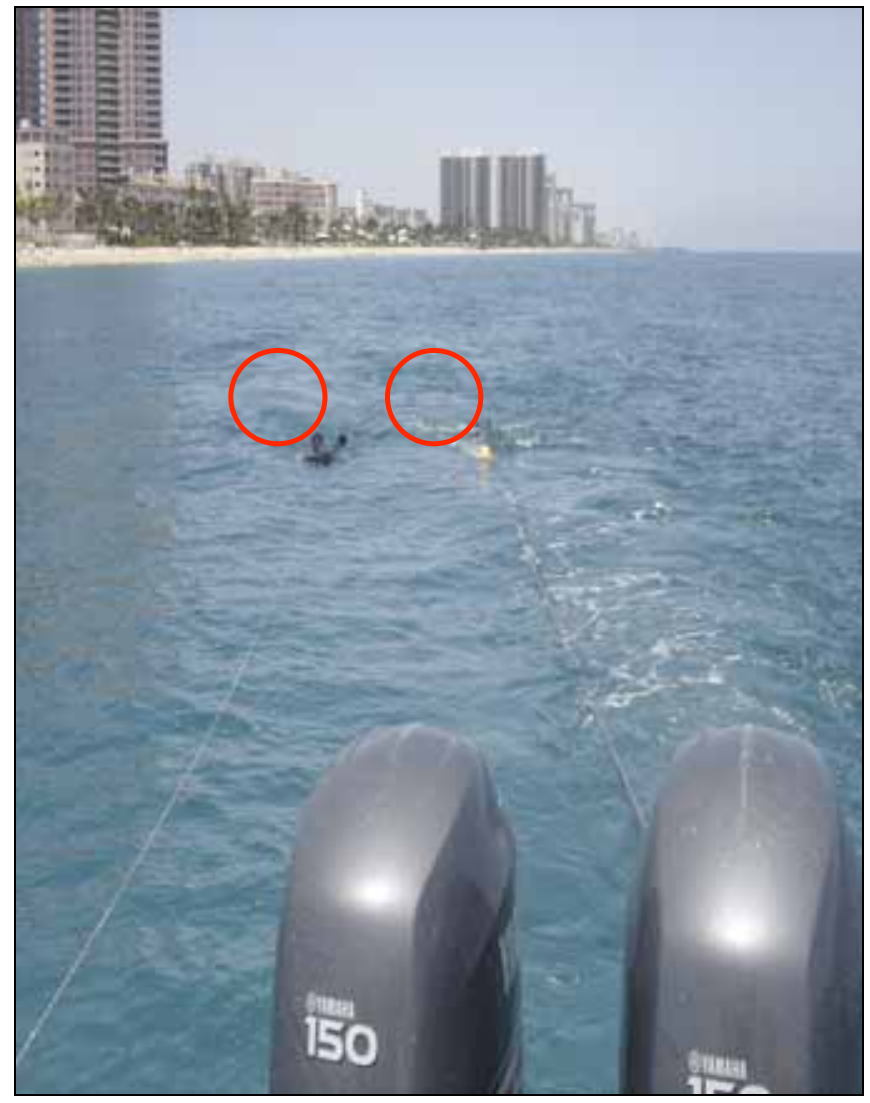

Fig. (3). View from the stern of the research vessel showing the 'Shark Fishing' surveying technique. The circles mark where the in-water observers are towed approximately $10 \mathrm{~m}$ behind the vessel.

\section{RESULTS}

Based on external morphological appearance, observers identified all of the sea turtles sighted during the survey as juvenile green turtles (Chelonia mydas L.); no other species, or size class, of sea turtles were observed during these investigations. Turtles were observed as either resting on the bottom, swimming slowly over the reef, or breathing at the surface. None of the observed turtles appeared distressed by researcher presence; rather, they usually departed by slow, yet deliberate swimming, in a direction perpendicular to the boat's heading (transect vector). Mean summaries from all surveying years are provided in Table $\mathbf{1}$.

\section{Countywide}

Surveys conducted from 2003 through 2007 yielded an annual mean of $46(+/-8 \mathrm{sd})$ juvenile green turtle observations throughout Broward County. The estimated density of turtles, based upon the length of the surveyed area $(\sim 31.6 \mathrm{~km}$ for Segments II and III), totaled at least one turtle observation every $0.69 \mathrm{~km}$. The minimum estimated abundance was 39 sightings during the pre-construction year 2004, while the maximum estimated abundance was 59 during the preconstruction year 2005. A $16 \%$ decrease in turtle observations was shown when the estimated abundance of preconstruction surveys (49) was compared to the postconstruction surveys (41). However, the largest difference was calculated between two pre-construction years (2004 v. 2005), which showed a $34 \%$ difference in turtle sightings. Post-construction surveys showed no differences and yielded the same estimated abundance (41) for two consecutive years. Ultimately, statistical analyses showed that the overall turtle abundance along Broward County's Segment II and III had not significantly differed during five years of surveys, which included three pre-construction and two postconstruction events (ANOVA; $\mathrm{df}=19, P=0.65$ ).

\section{Segment II}

Surveys along Broward County's Segment II control site recorded an annual mean of 31 (+/-6 sd) turtle observations over the five year study period. This constituted approximately $70 \%$ of all the turtles observed in this study, and on average, one turtle was sighted every $0.59 \mathrm{~km}$. During preconstruction years, the mean number of turtles observed was $33(+/-8 \mathrm{sd})$ per year. There was a decrease of $24 \%$ in mean turtle sightings between the pre-construction years of 2003 and 2004. Furthermore, the lowest observation mean was recorded in the pre-construction year of 2004, with 25 turtle sightings, whereas, the highest observation average was recorded the following pre-construction year with 41 turtle sightings; a differential of approximately $40 \%$.

During post-construction surveying years, the mean number of turtles observed was $29(+/-2$ sd) per year, with only a $3 \%$ difference in observations (one turtle sighting) among both post-construction surveys. Even though there was a decrease of $27 \%$ between the 2005 pre-construction survey $(m=41)$ and the 2006 post-construction survey $(m=30)$, there was only a $12 \%$ difference between the overall pre-construction and post-construction survey means. Overall, no significant variation in the turtle population was detected within the control site of Segment II between preconstruction and post-construction events (Mann Whitney rank sum $\mathrm{U}$ test, $Z=1.07, P=0.29, \alpha=0.01$ ).

\section{Segment III}

Over the five year study period, an annual mean of 14 $(+/-3$ sd) turtle observations was recorded within the Segment III experimental area. A density average was calculated to equal one turtle observation every $0.95 \mathrm{~km}$. The mean number of turtles during pre-construction years was $16(+/-2$ sd) per year. Similarly to Segment II, there was first a decrease $(7 \%, 2003$ v 2004), followed by an increase $(22 \%$, $2004 \mathrm{v}$ 2005), in the observation means during preconstruction events. Post-construction surveys yielded a mean of $12(+/-1 \mathrm{sd})$ observations per year. There was only an $8 \%$ difference (one turtle observation) among both the post-construction events in Segment III. While the lowest average mean was recorded in 2006 (post-construction), with 11 sightings, the highest average mean (18) was recorded one year prior in 2005 (pre-construction). This proved to be the largest differential between surveys in Segment III, with an approximate $39 \%$ decrease in sightings. As a result, there was a $25 \%$ difference between average pre-construction (16, $\mathrm{n}=3)$ and post-construction $(12, \mathrm{n}=2)$ observations in Segment III. Overall, changes within the Segment III juvenile turtle population were calculated to be right at the significance threshold for pre- versus post-construction events (Mann Whitney rank sum $U$ test, $Z=2.57, P=0.01, \alpha=0.01$ ).

Specifically within the Segment III experimental area, a majority of the post-construction turtle sightings took place parallel to beach fill reaches (R-86 to R-92; R-99 to R-128) 


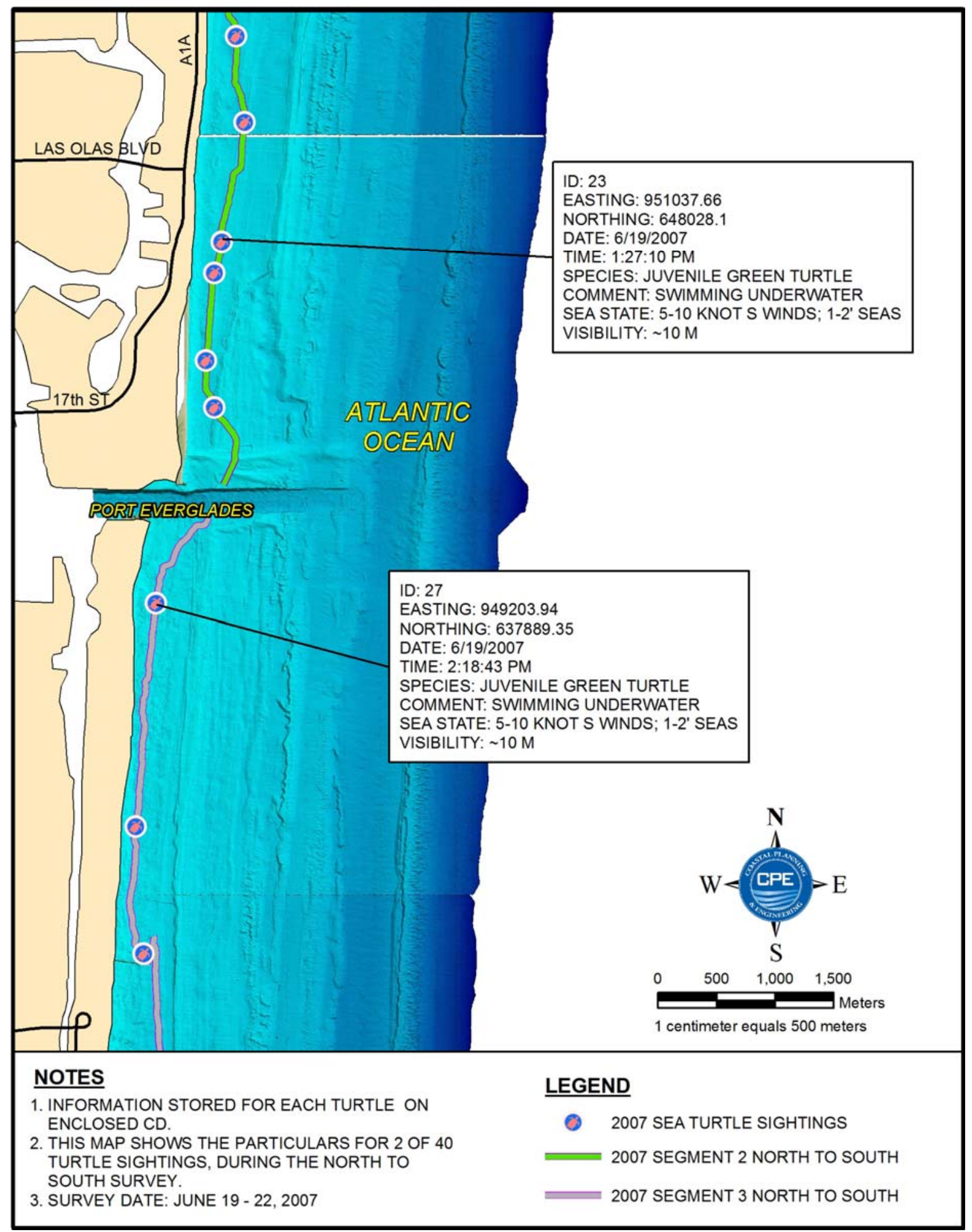

Fig. (4). Excerpt from the Broward County Sea Turtle Geodatabase showing positional and descriptive information for individual turtle sightings. The following figure in NTS.

of the shoreline (Fig. 5). In 2006, $86 \%$ of juvenile green turtles observed within the experimental area did not avoid areas within proximity of beach construction activities. During the first post-construction survey, three turtles were observed in the nearshore along the JUL shoreline, whereas 15 turtles were observed on reefs along the HHD shoreline. Only three turtles were sighted with the no-fill zone between R-92 and
R-99. Similarly, in 2007, 91\% of all turtles observed in Segment III aggregated to nearshore reef patches that fell within a possible zone of influence from the Broward County Shore Protection Project. Two turtles were observed along the JUL shoreline and 19 turtles were observed along the HHD shoreline; only two turtles were recorded within the designated no-fill zone of Segment III. 
Table 1. Results from All Surveying Years, Including Three Pre-Construction and Two Post-Construction Events. Numbers Listed Under "Segments" are Turtle Sightings During the North to South (N-S) and South to North (S-N) Surveys, and their Actual Mean. The Two Mean Values, Added Together, Yield an "Estimated Abundance" for the Turtles in Both Segments During that Survey Year

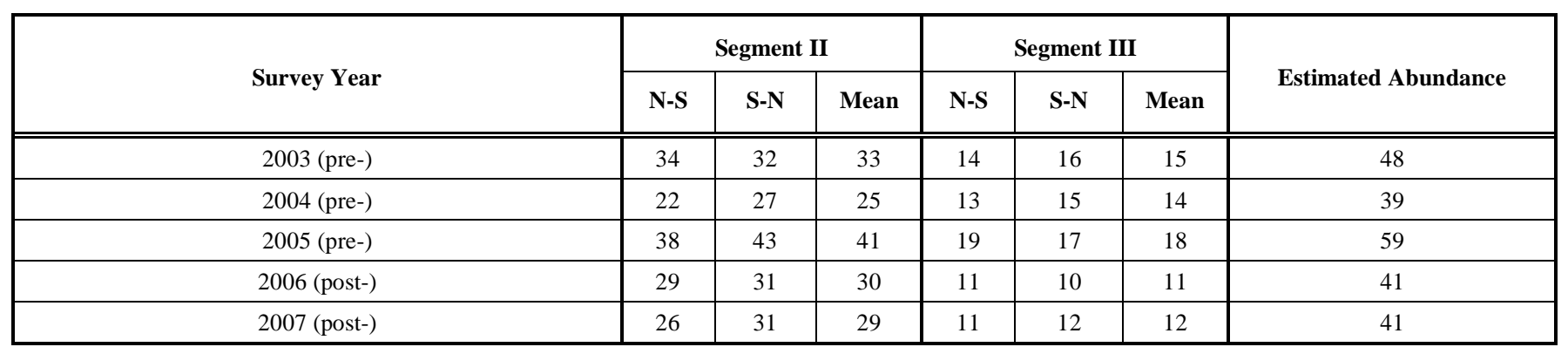

\section{DISCUSSION AND CONCLUSION}

This pilot study is among the first to estimate juvenile green turtle populations and the possible effect shoreline protection measures may have on their distribution within nearshore waters. Surveys were carried out for five consecutive years and focused on the number and location of juvenile turtles sighted before and after construction of the Broward County Shore Protection Project. Through spatial analyst tools, it was determined that the distribution of green turtles in the nearshore of Broward County was not adversely affected by beach nourishment.

\section{Surveying Technique}

This study utilized the 'Shark Fishing' surveying method to accurately estimate the overall abundance and distribution of juvenile green turtle populations within the nearshore waters of Broward County [8]. Other census methods have included either highly invasive (e.g. live netting) or farther removed (e.g. surface head counting) procedures. Live active netting puts a tremendous stress on the captured turtles and requires a lengthy permitting process to initiate [11]. Surface head counting removes the researcher from observing the essential reef habitats juveniles are aggregating to; thus, supplying a less accurate record of foraging distribution. Whereas these techniques may be the preferred choice in low underwater visibility areas, the 'Shark Fishing' in-water surveying method allows for the most precise account of juvenile green turtle site fidelity along the nearshore reefs of southeast Florida [8]. Even though turtles are never handled or disturbed, researchers are able to record accurate coordinates of the tur-

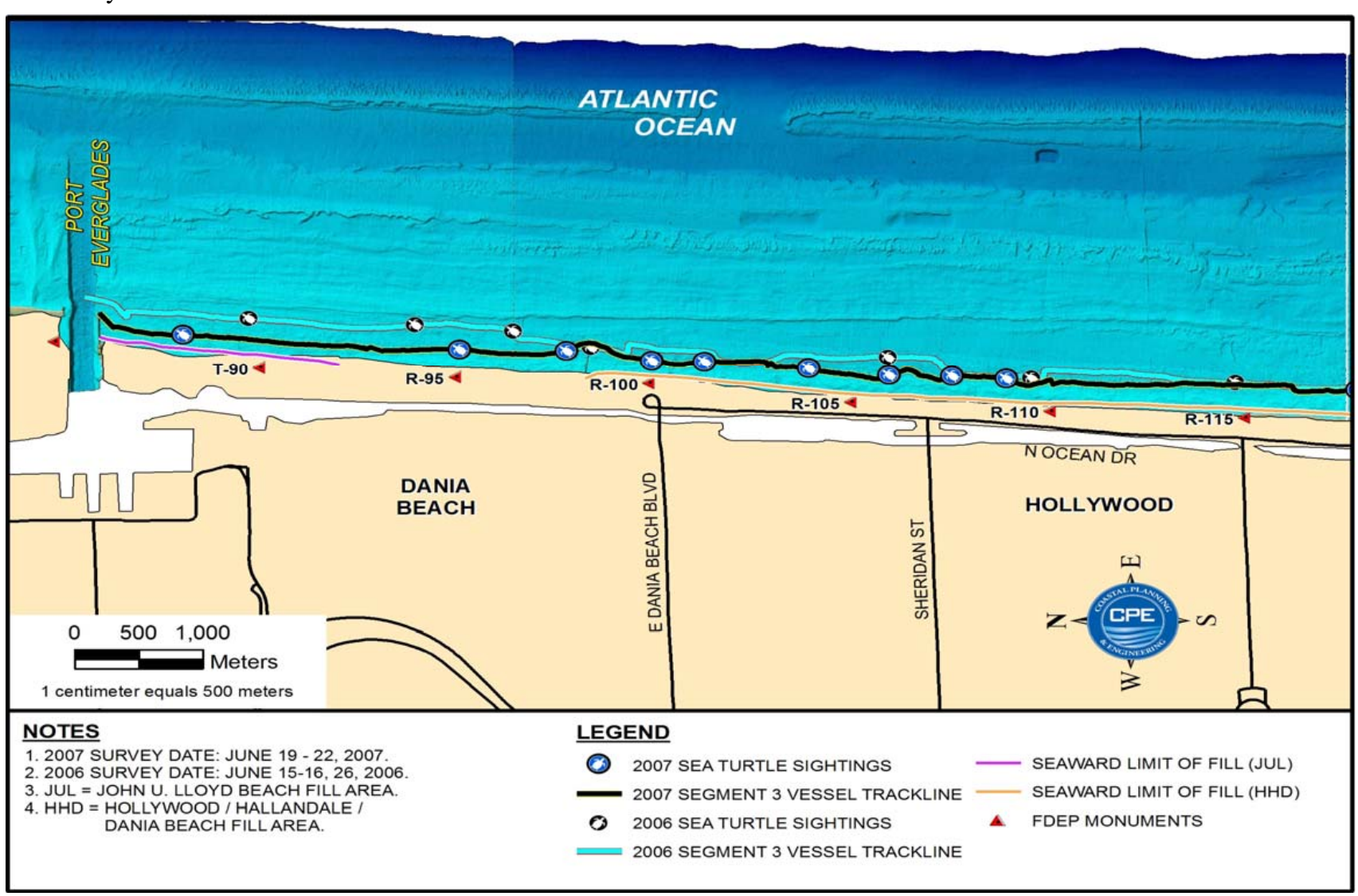

Fig. (5). Excerpt from the Broward County Sea Turtle Geodatabase showing that a majority of post-construction turtle sightings occurred parallel to beach renourishment reaches (JUL and HHD) along the shoreline. The following figure is NTS. 
tles' location along the reef while being able to observe the juvenile's behavior within the developmental habitat.

Previous 'Shark Fishing' surveys have shown the effectiveness of the in-water protocol. A quality assurance/quality control of the 'Shark Fishing' procedure was carried out where turtles were marked with non-toxic antifouling paint to identify individuals [12]. Surveys then revealed that the frequency of recounting the same turtle, on the same day, was less than five percent. In addition, Makowski et al. (2005) [8] reported the results from a 'Shark Fishing' survey over two consecutive summers along the nearshore reefs of Palm Beach County, Florida. During the summer of 2001, 62 juvenile green turtles were observed along an approximately $12 \mathrm{~km}$ length of reef habitat located in Central Palm Beach County, parallel to the Town of Palm Beach shoreline. All sea turtles sighted were seen foraging over reef patches close to shore. Likewise, a 2002 survey of the same habitat resulted in an increase $(n=79)$ in turtle observations, with no sea turtles seen over sandy bottoms of equal depth. These in-water surveys proved that juvenile green turtle abundance and distribution could be consistently recorded along the same nearshore resource over time [8].

\section{Abundance}

The estimated abundance totals from this study offer an accurate 'snapshot' of the entire juvenile population aggregating to the nearshore reefs of Broward County. According to the census data, the juvenile population means showed periods of fluctuation during the pre-construction events. Surveys prior to the construction of the Broward Shore Protection Project revealed a similar trend of variation among the Segment III experimental area and the Segment II control site. From 2003 to 2004, there was a decline in turtle observations for both Segments, with a $24 \%$ decrease in Segment II and a $7 \%$ decrease in Segment III. However, in the following preconstruction year of 2005, the largest differential of all the surveys was recorded. From 2004 to 2005, there was an increase of turtle observations in both Segments II and III of $39 \%$ and $22 \%$, respectively, suggesting that this population of juvenile green turtles have a natural tendency to slightly fluctuate in number.

Other studies $[8,13]$ have also shown natural annual fluctuations in the nearshore aggregation of juvenile green turtle populations. Bjorndal et al. (2005) [13] found that juvenile green turtle populations at Conception Creek and Union Creek, Great Inagua, Bahamas, had successive phases of increase, decrease, and stability. These annual changes were attributed to changes in the immigration of juveniles, suggesting that migratory tendencies of immature greens lead to different aggregation patterns $[13,14]$. This is further reinforced by the increase in hurricane activity around the Florida peninsula between the years 2004 to 2006 (e.g. Hurricanes Charley, Frances, Jeane, Ivan, Katrina, Rita, Dennis, Wilma). If a prevalence of cyclonic activity altered the migration patterns of juvenile greens, then fluctuations in the population dynamic would be evident; for example, recording variations in the estimated abundance of turtles during surveys in $2004(m=39)$, $2005(m=59)$, and $2006(m=41)$.

Even though there was a decrease in turtle observations one year after completion of the Broward County Shore Protection Project, post-construction surveys recorded a juvenile population that had become static in nature. From 2005 to 2006, a universal decline in turtle observations was seen at both the experimental area (Segment III, 38\%) and the control site (Segment II, 27\%). This decline is suspected to be a function of increased hurricane activity negatively shifting the macroalgae community dynamics along Broward's nearshore reefs, thereby reducing nutritional resources for maturing juveniles [15]. However, the decrease in observed turtles proved to be a single event, and the population stabilized with a similar estimated abundance total $(m=41)$ between both postconstruction surveys.

Overall, the abundance of juvenile green turtles showed a common decline in both the Segment III experimental area (25\%; 4 turtle observations) and the Segment II control site $(12 \%$; 3 turtle observations) between pre- and postconstruction surveys. And while the Segment II control site did not show significant changes $(P=0.29)$ in population size during this study, the Segment III experimental area was shown to be right at the significance threshold $(P=0.01)$ for abundance variability. Even so, the abundance of juvenile green turtles along the nearshore of Broward County, Florida had not significantly changed during five years of in-water surveys (ANOVA; $\mathrm{df}=19, P=0.65$ ), which included the completion of the Broward County Shore Protection Project. This demonstrated that the nearshore reefs of Broward County continue to serve as an important area of aggregation and development for growing juvenile sea turtles.

\section{Distribution}

One of the goals in this study was to determine if the distribution of juvenile green turtles would change as a result of the Broward County Shore Protection Project. More specifically, would the aggregating turtles completely avoid available nearshore resources parallel to beach construction activities? Pre-construction surveys revealed the distribution of juveniles were concentrated along the first landward reef tract $(\leq 8 \mathrm{~m}$ deep) of Broward County, where marine vegetation (i.e. macroalgae and seagrass) proliferated in the highest abundance. Prekel et al. (2007) [16] reported that at least seven of the macroalgae genera growing on Broward County's nearshore reefs serve as a preferred food source for juvenile green turtles. These genera included: Acanthophora, Bryothamnion, Dasycladus, Dictyota, Gracilaria, Hypnea, and Jania.

After evaluating the location fixes of foraging turtles postconstruction of the Broward Shore Protection Project, it was determined that juvenile greens continued to utilize shallow developmental habitats within proximity to the beach nourishment. Specifically within the Segment III project area, 89\% of the turtles sighted (39 of 44) during post-construction surveys were recorded along reefs adjacent to the beach fill areas. A majority (87\%) of these observations took place parallel to the HHD shoreline (R-99 to R-128). Receiving approximately 1.39 mcy of sand, the HHD shoreline was the most heavily constructed reach of Segment III. Even so, juvenile green turtles were observed to actively forage within the nearshore along this stretch of beach.

Furthermore, the distribution of juvenile turtles was not skewed towards the Segment II control site during postconstruction surveys. It had been postulated that the juvenile population could possibly become disturbed and aggregate exclusively to Segment II after beach construction had ceased, 
putting an increased stress on food resources along those reefs. However, post-construction distribution trends remained similar to the pre-construction surveys. Approximately, $72 \%$ of the turtles observed in post-construction surveys were distributed along Segment II, which was similar to the percentage of turtles $(67 \%)$ observed in the pre-construction years. By maintaining a sub-population of juvenile green turtles in both Segments II and III, a more evenly distributed foraging pressure on Broward County's reefs is sustained, ensuring that benthic vegetation will be allowed to grow in the wake of heavy cropping from the previous year [16].

\section{Conservation Implications}

Information on the abundance and distribution of juvenile green turtles occupying nearshore developmental habitats is vital to the conservation effort of this endangered species. Such population estimates provide answers to ecological questions that are necessary for understanding habitat use and life histories of immature sea turtles. For example, are these juvenile populations below the carrying capacity of the habitat, or do they exist at the niche threshold? If the latter applies, then habitat protection would be a recommended action.

This monitoring also allows sea turtle managers to know where juvenile turtles are concentrated in space before they can adequately protect these populations. In particular, beach nourishment projects can potentially pose a real threat when sand is pumped from offshore borrow sites to the shore. Following beach restoration, the possibility of compromising nearshore hardbottom substrates through sediment coverage still remains. If the abundance of nearshore resources becomes limiting for juvenile green turtles, such a loss can have a devastating effect on that specific population structure. These surveys aid in estimating such losses, and for devising sound strategies to mitigate against their effects. An annually updated sea turtle geodatabase has been implemented with this study and allowed managers to assess any effects that beach nourishment activities may have on resident sea turtle populations in Broward County. By keeping an archived record of inwater sea turtle observations, population abundance and distribution of juvenile sea turtles can be analyzed and applied to protect not only the turtles themselves, but also the nearshore resources essential to their development.

\section{ACKNOWLEDGEMENTS}

Financial and logistical support was provided by the Broward County Environmental Protection \& Growth Management Department, Florida Department of Environmental Protection, Florida Fish \& Wildlife Conservation Commission, and Coastal Planning \& Engineering, Inc. We would like to thank the following individuals for their generous contributions to this research: P. Bardes, M. Bauer, A. Buchar, T. Campbell, A. Delaney, C. Finkl, L. Floyd, A. Hannes, S. Prekel, S. Tate, and H. Vollmer.

\section{REFERENCES}

[1] Musick JA, Limpus CJ. Habitat utilization and migration in juvenile sea turtles. In: Lutz PL, Muscik JA, Eds. The biology of sea turtles. Boca Raton, CRC Press 1997; 137-63.

[2] Limpus CJ, Walter DG. The growth of immature green turtles (Chelonia mydas) under natural conditions. Herpetologica 1980; 36: 16265.

[3] Limpus CJ, Couper PJ, Reed MA. The green turtle Chelonia mydas in Queensland: Population structure in a warm temperate feeding area. Mem Queensl Mus 1994; 35(1): 139-54.

[4] Bresette MJ, Gorham J, Peery B. Site fidelity and size frequencies of juvenile green turtles (Chelonia mydas) utilizing near shore reefs in St. Lucie County, Florida. MTN 1998; 82: 5-7.

[5] Seminoff JA, Resendiz A, Nichols WJ. Home range of green turtles Chelonia mydas at a coastal foraging area in the Gulf of California, Mexico. Mar Ecol Prog Ser 2002; 242: 253-65.

[6] Makowski C, Seminoff JA, Salmon M. Home range and habitat use of juvenile Atlantic green turtles (Chelonia mydas L.) on shallow reef habitats in Palm Beach, Florida, USA. Mar Biol 2006; 148:1167-79.

[7] National Marine Fisheries Service and U.S. Fish and Wildlife Service. Recovery plan for U.S. population of Atlantic green turtle. National Marine Fisheries Service, Washington, D.C. 1991.

[8] Makowski C, Slattery RP, Salmon M. "Shark Fishing": A method for determining the abundance and distribution of sea turtles on reef habitats. Herpetol Rev 2005; 36(1): 36-8.

[9] Olsen Associates, Inc. and CPE. Broward County Shore Protection Project - Segment III, Post-Construction Engineering Summary Report. Report submitted to the Broward County Environmental Protection Department, Broward County, FL, and the Florida Department of Environmental Protection Bureau of Beaches and Coastal Systems, Tallahassee, FL.; Jacksonville, Florida; Olsen Associates, Inc., 2007; pp. 1-58.

[10] Wershoven R, Wershoven J. A survey of juvenile green turtles and their resting and foraging habitats off Broward County, Florida. Unpublished report to the Florida Department of Natural Resources, Division of Marine Resources, Broward County, Florida; 1988; pp. 135.

[11] Ehrhart LM, Ogren LH. Studies in Foraging Habitats: Capturing and Handling Turtles. In: Eckert KL, Bjorndal KA, Abreu-Grobois FA, Donnelly M, Eds. Research and Management Techniques for Conservation of Sea Turtles. IUCN/SSC Marine Turtle Specialist Group Publication; 1999; 4: 61-4.

[12] Makowski C. Home range and movements of juvenile Atlantic green turtles (Chelonia mydas L.) on shallow reef habitats in Palm Beach, Florida, USA. Boca Raton: Florida Atlantic University, Master's Thesis; 2004; pp. 33.

[13] Bjorndal KA, Bolten AB, Chaloupka MY. Evaluating trends in abundance of immature green turtles, Chelonia mydas, in the Greater Caribbean. Ecol Applic 2005; 15(1): 304-14.

[14] Bjorndal KA, Bolten AB, Chaloupka MY. Survival probability estimates for immature green turtles, Chelonia mydas, in the Bahamas. Mar Ecol Prog Ser 2003; 252: 273-81.

[15] Goldberg WM. The ecology of the coral-octocoral communities off the Southeast Florida coast: geomorphology, species composition, and zonation. Bull Mar Sci 1973; 23: 465-88.

[16] Prekel S, Hannes A, Barrett C, Ward G, Floyd L, Santos R, Reger C. Broward County Shore Protection Project - Segment III, 12-Month Post-Construction Nearshore Environmental Monitoring Report. Report submitted to the Broward County Environmental Protection Department, Broward County, FL, and the Florida Department of Environmental Protection Bureau of Beaches and Coastal Systems, Tallahassee, FL.; Boca Raton, Florida; Coastal Planning \& Engineering, Inc.; 2007; pp. 1-120. 